\title{
Typological Differences between English and Chinese Multi-verb Constructions
}

\author{
Mengmeng Tang \\ School of Foreign Studies, China University of Petroleum, China
}

Copyright $@ 2019$ by authors, all rights reserved. Authors agree that this article remains permanently open access under the terms of the Creative Commons Attribution License 4.0 International License

\begin{abstract}
English and Chinese are different in the composition of Multi-verb Constructions (MVCs), which refer to a series of verbs appearing in a mono-clause, without pauses or conjunctions. English MVCs contain a finite verb which inflects with tense, combined with non-finite forms (e.g., The boss encouraged Jerry to attend the meeting). Chinese MVCs are in the form of bare verbs or verbs with aspectual morphemes. From the perspective of finiteness, this article analyzes the typological differences of morphological finiteness in English and semantic finiteness in Chinese.
\end{abstract}

\section{Keywords Multi-verb Constructions, Finiteness}

\section{Introduction}

A multi-verb construction (MVC) involves a series of verbs appearing in a sentence, without pauses or conjunctions: the construction is a prosodically-independent unit, with each verb representing an action, an event phase or a state (e.g., the boss encourages Jerry to attend the meeting). English multi-verb constructions contain a finite verb which inflects with tense, combined with non-finite forms, which are either to-infinitives (to attend), gerunds (verb root plus -ing) or participles (verb root plus -ed). As non-finite verbs, they are neither inflected for grammatical tense nor undergo subject-verb agreement. Since Chinese has neither grammatical tense nor inflection, multiple verbs in comparable constructions take the form of bare verbs. In certain types of Chinese MVCs, such as verbs as subject or object (e.g., chōuyān wéihài shēntǐ jiànkāng, "smoke harm body health", smoking harms people's health), the series of bare verbs can be differentiated by a lexical cue. Specifically, matrix verbs can be identified because only they allow certain aspectual markers (e.g., adverb: yǐjīng, "already"; morpheme: le, the perfective marker). In certain types of Chinese MVCs (e.g., wǒ huí jiā chīfàn, "I go home have dinner", I go home to/ and have dinner), the two verbs are regarded as a compound predicate which refers to two verbs in one temporal category, with fixed order and no conjunctions [25], a language phenomenon without a counterpart in English.

There has been a long-running discussion on Chinese finite and non-finite verb distinctions (e.g., [5-8, 16-18, 21-24, 27-30]). Although there has been a considerable theoretical discussion of Chinese finiteness, no research has been undertaken to date from the perspective of the typological differences of semantic finiteness in Chinese and morphological finiteness in English in MVCs.

\section{Multi-verb Constructions}

Verbs are the core of a sentence. Descriptive linguists and comparative syntacticians have examined the typological differences in Multi-verb Constructions (MVCs) which comprise several verbs as a reflection of related events. This chapter will present the definition of MVCs, typological differences between Chinese and English MVCs, and the grammatical property "finiteness" in MVCs.

\subsection{Definition}

A multi-verb construction (MVC) is defined as the juxtaposition of two or more verbs in a monoclausal construction without pauses or conjunctions [2]. The construction is a prosodically-independent unit, with each verb representing an action, an event phase or a state (e.g., the boss encourages Jerry to attend the meeting).

MVCs have a broader range than serial-verb constructions according to the definitions of the former [2] and latter [2,25], although these two terms are employed interchangeably by certain researchers. A Serial-Verb Construction (SVC) is a string of verbs or verb phrases within a single clause that express simultaneous or immediately consecutive actions (e.g., Nǐ qù chīfàn, "you go have dinner"). They are often described as coding a single event [1], having a single grammatical subject, and having no connective markings, and are marked or understood as having the same grammatical categories, 
such as aspect, modality, negativity or positivity, and tense (e.g., you come see me anytime) [25].

There are typological differences in the form of MVCs, but they reflect a multidimensional continuum in all languages. For example, in typologically-distant languages, like English and Chinese, MVCs comprise different forms and features. In English, multiple verbs appear in the form of finite and non-finite verbs, with a clear morphological distinction between the two. Non-finite verbs are dependent on finite verbs, and each clause should contain only one finite verb in a clause. In contrast, as a language which lacks inflection and grammaticalized tense, Chinese multiple verbs either take the form of bare verbs or have verbs with aspectual adverbs or morphemes indicating their aspectual information. Time characteristics and internal relations are not realized morphologically. In the following section, details about English and Chinese MVCs will be provided.

\subsection{MVCs in English}

"Multi-verb constructions often consist of a main, inflected verb, and another verb marked as dependent on it. The form may vary (and so does terminology: in some traditions, the dependent form is called 'infinitive', in others 'participle' and in others 'gerund', or 'coverb" " $[1, \mathrm{p}$. 12]. In English, non-finite verbs ([-F] verbs) are neither inflected by grammatical tense nor undergo subject-verb agreement. Finite verbs $([+\mathrm{F}]$ verbs $)$ are in the position of predicates as matrix verbs, with non-finite verbs occupying other positions in the sentence, such as subject, object, object complement and adverbial. Examples are provided in example (1).

a. Seeing is one thing; doing is another.

b. I expected to enter graduate school in the fall.

c. Please allow me to introduce Mr. Smith to you.

d. I must leave now to get there on time.

In general, finite verbs have a compulsory tense and aspect, and non-finite verbs are not restricted by the number and person of the subject, are not used to express an event time independently, and are applicable in any position within a sentence, except for the predicate.

\subsection{MVCs in Chinese}

Li and Thompson [14] defined MVCs in Chinese as "a sentence that contains two or more verb phrases or clauses juxtaposed without any marker indicating what the relationship is between them" (p. 594). Chinese verbs do not have morphological inflections related to the person, gender, number, time, and can function as the subject, object, and complement in a sentence. Due to the lack of morphological distinctions among the juxtaposed verbs, the way in which the relations among the verbs are interpreted depends on the semantics of the verbs. $\mathrm{Li}$ and Thompson [14] ranked all Chinese sentence patterns in (NP)
V (NP) (NP) V (NP) as MVCs. Four types of MVCs are introduced in example (2).

a. Dúshū shì hăo xíguàn.

Read book be good habit

Reading books is a good habit. [15, p.37]

b. Tāmen xiăng huíjiā.

They want go home

They want to go home. [15, p. 249]

c. Wǒmen qǐng nǐ chàng yīzhī gē.

We invite you sing a song

We invite you to sing a song. [15, p. 485]

d. Wǒ măi piào jìnqù.

I buy ticket enter go

I bought a ticket and went in. (a)

I bought a ticket to go in. (b) $[15$, p. 595]

A pivotal sentence can be defined as follows: "of the two predicates in a sentence, the object of the first predicate (verb) is at the same time the subject of the second one" [15, p.485]. Two pieces of information arise from this definition: the two verbs are all regarded as predicates, and the frame of the structure is that a noun "pivot" connects V1 (verb one) and V2 (verb two), functioning both as the object of $\mathrm{V} 1$ and as the subject of V2. There are several sub-types of pivotal sentences from the semantic perspective, such as the pivotal predicate referring the "purpose and result of the action indicated by the first verb in the sentence" and the first verb "indicating the request, commend and cause" $[15$, p. 487]. Other pivotal sentence types include those with the first verb "yǒu" (have) and the pivotal predicate clarifying the state or the action of the pivot, or those with the first verb "shi”" (be) and the pivotal predicate explaining the first verb [15]. Even though the specific classification of pivotal sentences according to the semantics of the V1 and V2 varies, it is widely accepted that the pivotal predicate indicating the purpose or result of the action expressed by the first verb is the prototypical pivotal sentence. The present study will only involve prototypical pivotal sentences.

As mentioned by Li and Thompson [14], the case where two or more separate events in certain relations are juxtaposed together as a continuum is the typical and most common multi-verb construction. The two events appear to be separate but indeed are understood as being related to each other either as one consecutive event, the purpose, the alternation or the circumstance of another event [14]. Tao [25] calls these two events a compound predicate with a single grammatical subject, having no connective markings, and are marked or understood as sharing the same grammatical features, such as aspect, modality, negativity or positivity, and tense. Since no obligatory syntactic features indicate the specific relations between the two, many of the sentences within this group can be understood in more than one way. For convenience, later in this thesis, sentences with two or more separate events will be labeled "serial-event" sentences. The example of serial-event sentences shows that "go in" can be understood as both the 
purpose and the consecutive event of "buy a ticket". Thus, one Chinese serial-event sentence can be ambiguous, conveying the meanings expressed by two different English sentences.

In contrast to the apparent morphological difference between finite and non-finite verbs in English MVCs, indicating the non-finite verbs' dependency as well as the finite verbs' temporal information, multiple verbs in Chinese do not undergo any morphological changes. Given the differences existing at the morphological level between English and Chinese MVCs, a more abstract category of finite and non-finite distinction arises. Two questions follow the typological comparison:

a. Is the contrast between English and Chinese MVCs merely a reflection of the morphological differences, with similar concepts of finiteness?

b. Is the concept of finiteness absent from Chinese?

\section{Theoretical Underpinning}

\subsection{Definition of Finiteness and Its Development}

Curme [4] described finiteness as "to the finite forms of the verb, i.e., those limited by person, number and mood, are the infinite forms, i.e., those not thus limited, verbal forms without person, number, and mood." (p. 8448) Nikolaeva [20] proposes that "the development of syntactic theory starting from the 1960s led to an obvious departure from traditional assumptions. Finiteness was reanalyzed as something more abstract, essentially a clausal category that is only secondarily reflected in the form of the verb" (p. I).

The understanding of the division between finite and non-finite verbs has undergone a number of stages, which are respectively inflectional description (tensed forms vs. non-tensed forms), distributional description (predicate verbs vs. non-predicate verbs), parameters to determine the weakness of finiteness (being predicate, with tense, in agreement with the person and number of subject, being notional verbs or functional verbs, having mood markers), and the relations among the clauses (finite clauses vs. non-finite clauses).

The definition of finiteness has been developing, but, the afore-mentioned criteria apply mainly to inflectional languages, such as English. The question of how to view finiteness in a non-tensed language is important but complex, and a vast body of research on Chinese finiteness has contributed to this field.

\subsection{Theories on Semantic Finiteness}

Klein [9] states that "the distinction between finite and non-finite forms is not a mere surface phenomenon" (p. 1). He disagrees with the definition of finiteness based on tense, person, mood or other features for two reasons: "[f]irst, an inflectional category is not just a set of morphological changes; it is a cluster of formal and functional properties. Second, the finite/ non-finite distinction between verb forms is also made for many languages in which morphological marking is the exception rather than the rule ... for example, some fully-fledged languages, such as Chinese, lack inflection and are usually assumed to lack finiteness, although the absence of inflection does not exclude the existence of other means to express the same function". [10, p. 1-2]

Finiteness should be regarded as a grammatical category. A theory of finiteness based on "assertion" has been proposed [9-12]. This provides a theoretical basis for a comprehensive view of finiteness and has enhanced our understanding of its function.

It has been proposed that "on some abstract level of representation, there is a claim component, which is regarded as AST (assertion)" [9, p. 1], as in the sentence, "Jack went to school". There are two reasons why "went" is stressed here: to emphasize the time, as opposed to "Jack goes to school" and also to reinforce the claim, as opposed to "Jack did not go to school". The finiteness of the verb "went", therefore, comprises two elements: the relevant temporal interval (known as the "topic time" or TT) and the claim (known as the "assertion" or AST).

According to Klein [9], the finite component FIN [AST, TT] differs from its lexical content, which can be viewed as the non-finite "INF" component. "INF minimally consists of the verb and its arguments" [3, p. 268], so FIN operates on INF, as FIN [AST, TT] (INF); for example, Jack went to school, FIN [AST, TT] (INF [GO (JACK, SCHOOL)]). Finiteness can be realized when the abstract operator FIN is functioning on lexical content INF, which constitutes semantic finiteness. This can (or, in some languages, must) be reflected in morphological finiteness as in English, or cannot be reflected on the morphological level, as in Chinese.

Finiteness is possible if there is no verb inflection or tense, and adjectives can be predicates. Klein et al. [12] stated that topic time in Chinese is reflected as aspect, which indicates a time span that "precedes, follows, includes, or is included in the time of a situation with the properties indicated by the lexical content" (p. 753).

Therefore, it is important to draw a clear distinction between "morphological finiteness", "syntactic finiteness", and "semantic finiteness" [13], because "morphological finiteness is a property of verbs, whereas semantic finiteness is a property of utterances" [3, p. 267]. Semantically speaking, TT constitutes the time of an assertion, i.e., the time for which a situation holds true, while AST is the descriptive content of the sentence.

This theory of finiteness shifts concentration from the surface features of tense, person, number, and mood to the topic time and assertion. It facilitates the cross-linguistic study of finiteness, given that many languages do not have an obligatory morphological marking of tense, person, and 
number.

\section{Typological Comparison}

\subsection{Finiteness in Chinese MVCs}

The topic time of Chinese finiteness can be expressed by the aspectual particles, which are, respectively, "-le, -guò, -zhe". They follow the verb in a sentence and the particles express the perfective, progressive or experiential state of the verb:

- $\quad$ Perfective (PFV): -le

- $\quad$ Progressive/ durative (DUR): -zhe

- Experiential (EXP): -guò

Except for the aspectual particles, aspectual adverbs in Chinese also indicate the dynamic state of verbs. Particles and aspectual adverbs sometimes co-occur within a sentence, even though either may appear to indicate the aspectual meaning of the finite verb; for example, in "tā y̌̀-jīng huí le jiā", (he already go le home), "yǐ-jīng" (already) and "le" (perfective morpheme) co-occur. Aspectual adverbs differ from other time adverbs (e.g., "jīntiān" (today)) in that, in expressing time, they rely on the verbs' dynamic status while the other adverbs have independent temporal meanings. Li and Thompson [14] also noted that, usually, adverbs (e.g., "jīntiān" (today)) are movable, although some are unmovable (e.g. "yìjīng" (already)), with an unmovable position in a sentence, that only govern the dynamic states of the verb, and indicate the aspect of the verb. Xing [28] points out that three adverbs "yijīng" (already), "zhèngzài" (in the process) and "jiāngyào" (will) are unmovable adverbs that express the dynamic states of the modified verb.

\subsection{A Comparison between Chinese and English MVCs}

Based on the above analysis, Chinese semantic finiteness can be viewed as being marked by aspect, rather than tense, in which both particles and aspectual adverbs serve to mark the temporal information of the finite verb. In this section, aspectual particles and adverbs are used as a diagnostic method for distinguishing verbs in MVCs. By checking whether aspectual particles or adverbs can be added to the bare verbs in MVCs, the function of the verb can be established; that is, any non-finite verb with aspectual information would be ungrammatical in a sentence.

\subsubsection{Verbs as Subject or Direct Object}

In sentences with verbs as subject, aspectual particles or adverbs can only be added to the predicate verb, so the latter is the matrix verb or, in other words, it is the dynamic word or finite verb, while the verb subject is the non-finite verb. Example (3) shows how to detect finiteness using the method of broad morphology.

(1) Chouyān wēihài tā de jiànkāng.

V1 V2

Smoke harm his health

Smoking harms his health.

a. Chouyān yỉjīng wēihài le tā de jiànkāng.

Smoke Already Harm PFV His Health

Smoking has already harmed his health.

b. *Yỉjīng chouyān le wēihài tā de jiànkāng.

*already smoke PFV harm his health

The non-finite verb is "chouyān" (smoke), while "wēihài" (harm) is the finite verb, since aspectual markers can only be combined with "wēihài" (harm), and not with "chouyān" (smoke). The finite verb marks the assertion and temporal information.

In sentences with verbs as object, similarly, aspectual markers can only be combined with predicate verbs, and the verb object is a non-finite verb. This is illustrated in example (4).

(2) Tāmen tíngzhǐ gongzuò.

V1 V2

They stop work

They stop working.

a. Tāmen yỉjīing tíngzhǐ le gongzuò.

They already stop PFV work

They have already stopped working.

b. *Tāmen tíngzhǐ yỉjīng gongzuò le.

They stop already work PFV

So "tíngzhǐ" (stop) is the finite verb because it can be combined with aspectual markers, including adverbs in front of it and particles after it. In contrast, the verb-object "gongzuò" (work) is the non-finite verb, because no aspectual markers are allowed before or after it.

In comparison with English non-finite verbs as subject or direct object, Chinese also has a finite and non-finite distinction. The aspectual particles "le, guò, zhe" in Chinese are allowed in the predicate verb; for expressing the completion of the event, perfective particles are compulsory and cannot be changed; and particles are closely combined with the root in sentences with verbs as subject or direct object. English tense markers are compulsory for the predicate verb, closely combined with the root, and non-replaceable. Even though English is marked with tense markers while Chinese with aspect markers, Chinese sentences with verbs as subject or direct object and English non-finite verbs as subject or object sentences are similar at the semantic level.

\subsubsection{Pivotal Sentences}

In pivotal sentences, V1 is the predicate of the first subject and V2 the predicate of the second subject; however, the subject of V2 is also the object of V1, so it is complex and difficult to distinguish finite from non-finite verbs, and this has been hotly debated among linguists. Using the diagnostic method of broad morphology, it emerges that the aspectual adverb "yijīng" (already) can 
only occur in front of V1, while the aspectual particle "le" tends to follow V2, as shown in the example (5).

(1) Tā jiào wǒ cānjiā huiỳì.

$$
\text { V1 V2 }
$$

She order I attend meeting

She ordered me to attend the meeting.

a. Tā yỉjīng jiào wǒ cānjiā le huì yì.

She already order I attend PFV meeting

She had already ordered me to attend the meeting.

And I did attend it.

b. *Tā y̌̉jīng jiào le wǒ cānjiā huìyì.

She already order PFV I attend meeting

In this construction, the aspectual markers show inconsistency with regard to testing the finiteness of the two verbs: aspectual particles are usually combined with V2, which gives V2 temporal information. Xing [28] has examined pivotal constructions in the verb usage dictionary [19] and found that, of the 1,328 verbs contained therein $180(13.55 \%)$ can be used as V1 in pivotal constructions. In the pivotal sentences containing these 180 verbs, almost all the particles appear after V2 rather than $\mathrm{V} 1$. We thus argue that a pivotal sentence is a frame that should be regarded as a continuum. In the framework of the structure, V1 marks the starting point for a series of events and, V2 is the end point of that series of events, even though these two verbs do not share the same subject. As a continuum, aspectual adverbs should precede the starting point of $\mathrm{V} 1$, and aspectual particles should occur after the end point of V2.

The reminiscent English MVC counterpart seems to be sentences with nonfinite verbs as object complement, but in Chinese pivotal sentences, with aspectual markers after V2, both verbs indicate the aspectual information. Even though the sentence order and verbs' arrangement share some degree of similarity, they differ with regard to finiteness.

\subsubsection{Serial-event Sentences}

In sentences with two serial events, both verb 1 and verb 2 are applicable, with aspectual adverbs and morphemes, as shown in example (6).

(2) Wǒ măi piào jìn qù

$$
\text { V1 V2 }
$$

I buy ticket enter

I bought a ticket and went in.

I bought a ticket to go in.

a. Wǒ y̌̉jīng măi le piào jìn qù.

I already buy PFV ticket enter

I already bought a ticket to go in.

b. Wǒ yǐjīing măi piào jìn qù le.

I already buy ticket enter go PFV

I bought a ticket and went in.

Serial-event sentences have two possible interpretations: when V2 is the purpose of V1, the temporal information is with V1, and V2 is non-finite. When V1 and V2 are understood to be in consecutive time order, they compose an event continuum, indicate the starting and end point of the event, and are both finite.

In contrast, English sentences with nonfinite verbs as adverbial are similar with Chinese serial-event sentences, when the latter conveys the meaning of V2 as the purpose of V1. However, English only has one interpretation, and has no compound predicates to indicate the completion of both events represented by the two verbs.

The finiteness in different types of MVCs displays different characteristics, and it is difficult to draw a uniform distinction between finite and non-finite verbs in Chinese. The property of finiteness in Chinese, as revealed by the diagnostic test based on semantic finiteness theory, differs from morphological finiteness. It is implicit and can only be detected by the combinatory capability with aspectual adverbs or particles. In comparison, English has a direct, clear, uniform morphological difference between finite and non-finite verbs.

\section{Conclusions}

Chinese finiteness is realized by aspect [12], and aspectual particles and adverbs comprise the aspectual system. Chinese verbs as subject or object can be regarded as non-finite, as no aspectual markers can be added to either the subject or object, and so share a degree of similarity with English non-finite verbs as subject or object sentences. The difference lies in the form: English non-finite verbs as subject or direct object should take the form of "-ing" or "to infinitives", while Chinese verbs as subject or direct object are bare in the form. Chinese pivotal sentences have the same word order as English non-finite verbs as object sentences, but the pivot predicate with perfective morphemes as a part of the compound predicate indicates the completion of the event continuum. Serial-event sentences have more flexible interpretations, and aspectual particles can appear after either V1 or V2. V2 may be understood as the purpose of V1 without temporal information. It can also be interpreted as the consecutive event in the same temporal category with V1.

The current research shows that the cross-linguistic differences between Chinese and English MVCs vary on both the morphological and semantic level. These cross-linguistic differences may result in different problems for L2 learners from a semantic finiteness language background when learning a morphological finiteness language, and vice versa.

\section{Acknowledgements}

This study was funded by the China Ministry of Education Humanities and Social Sciences Youth Fund 
Project (project number: 2015050023) and the Fundamental Research Funds for the Central Universities (project number: 2462019YJRC005)

\section{REFERENCES}

[1] Aikhenvald, A. Serial verb construction in a typological perspective. In A. Aikhenvald \& R. M. W. Dixon (Eds.), Serial Verb Constructions: a cross-linguistic typology cross-linguistic typology. Oxford: Oxford University Press, $1-68,2006$.

[2] Aikhenvald, A. Y., \& Muysken, P. C. Multi-verb Constructions: a view from the Americas. Brill's Studies in the Indigenous Languages of the Americas, 3. Brill, Leiden, The Netherlands, 2011.

[3] Becker, A. The semantic knowledge base for the acquisition of negation and teh acquisition of finiteness. In H. Hendriks (Ed.), The Structure of Learner Varieties. Berlin, New York: Mouton de Gruyter, 263-314, 2005.

[4] Curme, G. O. Syntax: A Grammar of the English Language. Boston: D.C. Heath, 1931.

[5] $\mathrm{Hu}$, J., Pan, H., \& Xu, L. Is there a finite vs. nonfinite distinction in Chinese? Linguistics, Vol.39, No. 6, 1171148, 2001.

[6] Huang, C.-T. J. Move wh in a language without wh-movement. The Linguistic Review, 1, 369-416, 1982.

[7] Huang, C.-T. J. On the Distribution and References of Empty Pronouns. Linguistics Inquiry, Vol. 15, No. 4, 531574, 1984

[8] Huang, C.-T. J. Pro-drop in Chinese: A generalized control theory. In O. Jaeggli \& K. Safir (Eds.), The Null Subject Parameter (pp. 185-214). Dordrecht: Kluwer, 185-214, 1989.

[9] Klein, W. Assertion and finiteness. Issues in the Theory of Language Acquisition: Essays in Honor of Jurgen Weissenborn, 225-245, 1998.

[10] Klein, W. On Finiteness. In Semantics in acquisition. Springer Netherlands, 245-272, 2006.

[11] Klein, W. Finiteness, universal grammar, and the language faculty. Crosslinguistic Approaches to the Psychology of Language: Research in the Tradition of Dan Isaac Slobin, 333-344, 2009.

[12] Klein, W., Li, P., \& Hendriks, H. Aspect and assertion in Mandarin Chinese. Natural Language \& Linguistic Theory, Vol.18, No.4, 723-770, 2000.

[13] Lasser, I. Finiteness in adult and child German. Radboud University Nijmegen, 1997.

[14] Li, C. N., \& Thompson, S. A. Mandarin Chinese: A Functional Reference Grammar. Berkeley, Los Angeles, London: University of California Press, 1981.

[15] Li, D., \& Cheng, M. A Practical Chinese Grammar for Foreigners (Revised Edition. Beijing: Beijing Language and Culture University Press, 2008.

[16] Li, J., \& Liu, J. Finiteness and non-finiteness in Chinese. Chinese Language Learning, Vol.1, 19-24, 2005.
[17] Li, Y.-H. A. Abstract Case in Chinese. Los Angeles: University of Southern California, 1985.

[18] Li, Y.-H. A. Order and Constituency in Mandarin Chinese. Dordrecht: Kluwer, 1990.

[19] Meng, Z., Zheng, H., Meng, Q., \& Cai, W. Hanyu Dongci Yongfa Cidian [Chinese Verbs Usage Dictionary]. Beijing: Commercial Press Ltd, 1999.

[20] Nikolaeva, I. Finiteness: Theoretical and Empirical Foundations. Oxford: Oxford University Press, 2007.

[21] Shi, Y. Differences between Chinese finite and non-finite verbs. International Chinese Teaching, Vol.2, No.56, 23-27, 2001.

[22] Song, Y. Should Chinese have gerunds? Chinese Study, Vol.4, No.22, 2000.

[23] Tan, F. The expression of "generalization" and differences between finite and non-finite Verbs. In Paper presented at the the 4th International Chinese Teaching Conference, 1995.

[24] Tang, T. Chinese finite clause and non-finite clause. Language and Linguistics, Vol.1, No.1, 191-214, 2000.

[25] Tao, L. Serial verb construction in Mandarin Chinese: the interface of syntax and semantics. In Y. Xiao (Ed.) Proceedings of the 21st North American Conference on Chinese Linguistics (NACCL-21), Vol. 2, 209-228, 2009.

[26] Tsai, W. T. D. Tense anchoring in Chinese. In Paper presented at the the 4th Conference of European Association of Chinese Linguistics. Hungarian Academy of Sciences, Budapest, 2006.

[27] Wang, D. Nominalization and Verbalization in Contemporary Chinese: A Cognitive Linguistic Inquiry. Beijing: China Social Science Press, 2010.

[28] Xing, X. Pivotal Sentences in Modern Chinese. Beijing: Communication University of China press, 2004.

[29] Yang, B. Study of finiteness of Chinese verbs from covert category and clinisation. Contemporary Foreign Lanuage Study, Vol.8, 6-10, 2015.

[30] Yang, Y., \& Tsai, B. On the mechanism of inflection and finiteness of Chinese verbs. International Chinese Teaching, Vol.25, No.2, 159-174, 2011. 